\title{
Contemporary aspects in the assessment of quality and treatment of swimming pool water
}

\author{
Mariusz Dudziak ${ }^{1, *}$, Joanna Wyczarska-Kokot ${ }^{1}$, and Edyta Laskawiec $^{1}$ \\ ${ }^{1}$ Silesian University of Technology, Faculty of Energy and Environmental Engineering, Konarskiego 18, 44-100 Gliwice, Poland
}

\begin{abstract}
Recent reports in the literature relate to the identification of various substances in the pool water, including low-molecular weight pharmaceuticals that can react with chlorine residues contributing to the formation of a large group of irritant and toxic compounds. These substances are not covered by standard monitoring. As part of this work, the authors present information on the methods for assessing the quality of the swimming pool water. Common processes used in swimming pool water treatment systems were described. Previous experience of the authors in the use of a detailed assessment of the quality of the swimming pool water on the basis of toxicity tests was presented. The authors have researched the application of pressure driven membrane filtration for the improvement of the efficiency of the swimming pool water treatment.
\end{abstract}

\section{Introduction}

The latest literature reports on the identification of various low-molecular substances, including the pharmaceutical ones, in swimming pool water [1]. These compounds may react with chlorine residuals, leading to the creation of a large group of irritative and toxic compounds.

Swimming pool water is commonly treated by coagulation, filtration and disinfection processes [1-3]. However, the problem related to the management of washings has not yet been solved. In the case of this waste flux there are no uniform procedures.

This paper presents information on the methods used for the assessment of the quality of swimming pool water and the types of processes that are used in swimming pool water treatment systems. The authors' past experience in using various toxicity tests for detailed swimming pool water quality assessments was demonstrated. The authors also researched the use of pressure membrane filtration (ultrafiltration) and determined if it can improve the effectiveness of a swimming pool water treatment process.

\section{Swimming pool water quality assessment}

\subsection{Control}

Legal and natural persons running businesses in the swimming pool industry are responsible for health and safety of the bathers. As a result of that the individuals that are in charge of swimming pool facilities should control the swimming pool water and ascertain that it is of the best quality.

Health and safety of the bathers is guaranteed by [1-3]: operational pool water treatment devices, maintenance of correct hygienic and sanitary conditions in the swimming pool facility, constant intake of clean water, health and hygiene of the bathers.

Microbiological and physicochemical contaminants present in swimming pool water may be harmful to health and cause sickness. The most common ailments affecting people who visit swimming pools with inadequate water treatment are [2-3]: conjunctivitis, ear inflammation, pharyngitis, gastro-intestinal illnesses, skin diseases (fungal infections, dermatitides, impetigoes, warts) as well as allergies and asthmatic respiratory symptoms.

The assessment of the swimming pool water quality performed by a person managing the swimming pool facility comprises [1-3]: visual assessment of the pool water quality in particular swimming pool basins, control of the operation of devices in the swimming pool water circuit treatment system by measuring the parameters of water quality, i.e. water $\mathrm{pH}$, redox potential, free chlorine, water temperature and bounded chlorine.

The physicochemical requirements should only be an aid in the assessment of the swimming pool water. The most important are the results of microbiological tests and the evaluation of the state of the facility and devices after a sanitary inspection.

To correctly evaluate the quality of the swimming pool water and the effectiveness of its treatment system one should monitor not only the quality of water in the swimming pool basins, but also the quality of water from the mains (replenishing the losses and providing water for the retention tanks) and the quality of the filtrate which determines the filtration effectiveness. 


\subsection{Microcontaminants}

Among the organic microcontaminants present in swimming pool water, the literature concentrates primarily on the substances from the group of disinfection byproducts (DBP), that is chloroform and other trihalomethanes (THM) [2]. However, in 2002, Lambropoulou et al. [3] documented the presence of compounds coming from UV filters that are used in cosmetics (2-hydroxy-4-methoxyphenyl BP3) and (2ethylhexyl-4-dimethylaminobenzoate OD-PABA). It means that these compounds were introduced to the swimming pool water by the bathers. Other researchers also confirmed the presence of compounds from UV filters in swimming pool water (Table 1) [4-8]. The analysis of Table 1 leads to a conclusion that the presence of UV filters in swimming pool water is a common occurrence and that the concentrations of particular compounds depend both on the type of the pool and its location (country). The concentration levels depend also on the type of the compound.

Ekowati et al. [8] tested the swimming pool water not only for the presence of compounds from UV filters, but also for a wide range of pharmaceutic substances. The water samples were collected from 17 swimming pools in sports centers and hotels in Catalonia, Spain. Among the pharmaceutical substances, 10 compounds were identified, i.e. atenolol, carbamazepine, hydrochlorothiazide, metronidazole, ofloxacin, sulfamethoxazole, paracetamol, ibuprofen, ketoprofen and phenazone. The highest concentration was found for a diuretic substance, hydrochlorothiazide, which amounted to $904 \mathrm{ng} / \mathrm{dm}^{3}$. The most commonly detected substance was carbama-zepine which was found in more than half of all analysed water samples $(53 \%, 27 / 51)$. The pharmaceutical substances were detected most frequently in spas.
On the other hand, Wenget al. [9] identified 3 substances of very different origin, i.e. N,N-diethylmeta-toluamide - used as an insecticide, caffeine natural psychoactive substance and tris(2-chloroethyl) used as a flame retardant. It was also determined that the concentration of the insecticide was changing from season to season, reflecting the varying intensity of its use. It is very rare for this insecticide to be used in winter and, therefore, its highest concentration was detected in summer (approx. $2087 \mathrm{ng} / \mathrm{dm}^{3}$ ). The concentrations of the other two substances, i.e. caffeine and tris(2-chloroethyl), were also the highest in summer. Caffeine may be introduced to swimming pool water with secretions, such as sweat and urine. The source of the flame retardant was not determined.

Microcontaminants present in swimming pool water may lead to its toxicity. Therefore, the assessment of swimming pool water should be aided by an ecotoxicological analysis.

\subsection{Toxicological assessment}

Ecotoxicological tools are commonly used in assessments of negative impact of chemical substances on live organisms. The indicator organisms used in biotests are characterized by varying sensitivity to a wide range of organic and inorganic compounds. The results of the biotests are obtained by observing the influence of toxicants on metabolism, decreased population, growth and development changes in the indicator organisms [10].

Among the test organisms there are bacteria, as well as animal and plant organisms. The analysis of the biotests results is based on toxicity classification of a particular sample. One of the most common toxicity classifications of samples was presented in Table 2 .

Table 1. Concentration of UV filters in swimming pools.

\begin{tabular}{|c|c|c|c|c|c|}
\hline \multirow{2}{*}{ Matrix } & \multicolumn{3}{|c|}{ Concentration $\left[\mathrm{ng} / \mathrm{dm}^{3}\right]$} & \multirow{2}{*}{ Country } & \multirow{2}{*}{ Literature } \\
\hline & BP3 & $4 \mathrm{MBC}$ & OD-PABA & & \\
\hline \multirow{3}{*}{ Swimming pool } & $2400-3300$ & - & $<900-2000$ & Greece & [3] \\
\hline & $4.2-5.7$ & 5.4-6.9 & - & Greece & [4] \\
\hline & $103-400$ & $<146-330$ & $<37$ & Slovenia & [5] \\
\hline Baby pool & 1200 & 10000 & - & \multirow{2}{*}{ Germany } & \multirow[b]{2}{*}{ [6] } \\
\hline Swimming pool & - & 600 & - & & \\
\hline Public pool & $<110$ & $<200$ & $<70$ & \multirow{6}{*}{ Spain } & [7] \\
\hline Private pool & $<0.1-4.87$ & $<0.4-5.60$ & $<0.1$ & & \multirow{5}{*}{ [8] } \\
\hline Indoor swimming pool & $<0.1-15.17$ & $<0.4-35.9$ & $<0.1-2.0$ & & \\
\hline Outdoor swimming pool & $<0.1-1.77$ & $8.6-12.1$ & $<0.1$ & & \\
\hline Indoor children & $<0.1-1.97$ & $8.1-45.4$ & $<0.1$ & & \\
\hline Spa & $<0.1-1.07$ & $<0.4-69.3$ & $<0.1$ & & \\
\hline
\end{tabular}

Table 2. Classification of toxicity [10].

\begin{tabular}{|c|c|}
\hline Effect, $\%$ & Toxicity class \\
\hline$<25$ & non toxic \\
\hline $25-50$ & low toxicity \\
\hline $50.1-75$ & toxic \\
\hline $75.1-100$ & high toxicity \\
\hline
\end{tabular}


The in-house research [11-13] on the use of biotests as a tool supporting the physicochemical analysis of the swimming pool water allowed to establish the preliminary procedures of their use.

The samples for the ecotoxicological tests may be taken from various places in the swimming pool water circuit what allows to control the water quality on every stage of its treatment, preliminary procedures of their use. The samples for the ecotoxicological tests may be taken from various places in the swimming pool water circuit what allows to control the water quality on every stage of its treatment, i.e. from the system water supply to waste fluxes from the washings of pressure filters. The samples may be collected to both glass bottles and plastic containers because it was proven that the material the containers are made of does not significantly influence the quality of the sample and the biotests results. The collected samples may be subjected to the biotests directly because there is no need for additional preparatory procedure. It is of vital importance that the biotests be accompanied by a basic physicochemical analysis of the sample. The tests results revealed that the increased toxicity was caused by free chlorine concentration in the tested samples [13]. As a result of that, it was necessary to establish a proper time gap or dechlorinate the sample, limiting the influence of chlorine on the biotest results.

During the in-house research [11-13] various indicator organisms at different levels of nature organization were used. Some of the tests involved the simultaneous use of a few indicator organisms that allowed to establish the differences in their sensitivity. For instance, while assessing the toxicity of samples [11], three indicator organisms were used, i.e. Aliivibrio fischeri, Daphnia magna and Chaoborus flavicans whose sensitivity to toxicants varied greatly. Fig. 1 shows the results of biotests for the sample of water from the mains, water from the swimming pool basin and waste water flux - washings. Microtox ${ }^{\circledR}$ test showed the toxic effect of water from the swimming pool basin and washings on Aliivibrio fischeri bacteria. Bioluminescence inhibition for these samples amounted to $65 \%$ and $53 \%$, respectively. In the remaining biotests, the toxicity of the swimming pool water sample on the indicator organisms was low (Daphnia m. 8\% and Chaoborus f. 22\%). In the case of the washings sample, the tested organisms showed varying sensitivity to the ingredients present in it. The mortality rate of diptera larvae was approx. $90 \%$ what indicates that the sample is highly toxic (Table 2). However, Daphia magna test results show that the toxicity of the same sample is low (mortality rate of crustacea of approx. 42\%). These results show that the sensitivity of indicator organisms varies greatly.

Among the indicator organisms employed in phytotests, aquatic plants from the Lemnaceae family, including Lemna minor, are also widely used. They are characterized by small size, simple structure and fast growth. These organisms are especially sensitive to surfactants of hydrophobic properties that concentrate at liquid-air interface [14]. During the in-house research [11], it was determined that phytotests allowed to specify which swimming pool water samples stimulate or inhibit the plants growth. This aspect is especially important as it allows to decide whether, for instance, the washings flux from the swimming pool installation may be used to water the greenery surrounding swimming pool facilities.

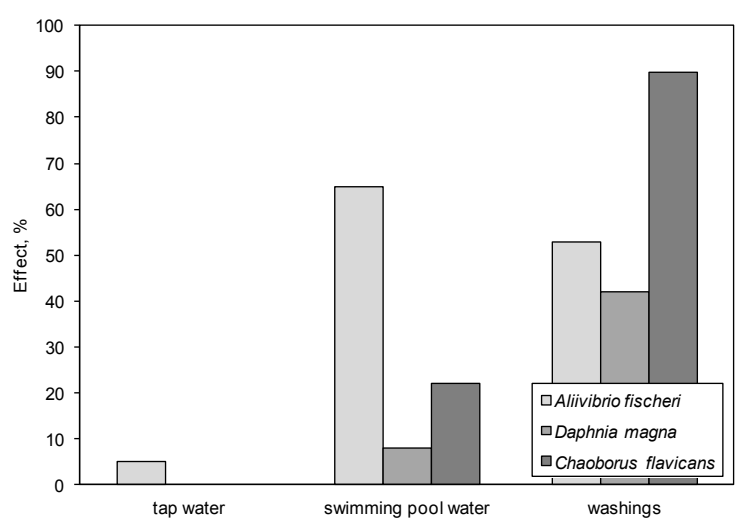

Fig. 1. Toxic effects in the Microtox ${ }^{\circledR}$ test, and in testing the survival of Daphnia magna and Chaoborus flavicans individuals [11].

Full toxicological evaluation may be an important tool supporting the standard physicochemical methods of swimming pool water quality assessment. The test results show that the sensitivity of indicator organisms varies greatly. The simultaneous use of a few biotests allows to establish more precisely the influence of chemical substances present in the tested samples on various live organisms. The phytotests, in turn, make it possible to determine both the stimulating and the inhibiting effect of the swimming pool water or washings samples on the growth and development of plants.

\section{Processes and methods of swimming pool water treatment}

The processes and methods for the treatment of water in the swimming pool circuit should allow for the accumulation of contaminants introduced to the swimming pool water by the bathers and provide a dose of disinfectant guaranteeing the removal of microorganisms from the swimming pool water basin.

The basic water treatment systems for sports and leisure swimming pools should consist of a filtration process, and specifically a surface coagulation run in filters with a sand and gravel bed, and a chlorine disinfection process, with the use of sodium hypochlorite (preferably, produced on site, in the process of membrane electrolysis).

The methods for the treatment of swimming pool water that allow to obtain water of quality and hygienic parameters compliant with the norms [15] include:

- filtration in sand filters + chlorine disinfection + $\mathrm{pH}$ correction,

- surface coagulation in sand filters, multilayered ones or with a layer of hydro-anthracite + chlorine disinfection $+\mathrm{pH}$ correction, 
- surface coagulation + ozonization + sorption filtration + chlorination $+\mathrm{pH}$ correction,

- surface coagulation + ozonization + filtration in a multilayered bed (including the sorption layer) + chlorination $+\mathrm{pH}$ correction,

- ozonization + sorption filtration + chlorination + $\mathrm{pH}$ correction,

- surface coagulation in multilayered filters + ozonization of part of the circuit water flux + chlorination $+\mathrm{pH}$ correction,

- surface coagulation in multilayered beds $+\mathrm{UV}$ irradiation + chlorination $+\mathrm{pH}$ correction .

\subsection{Filtration}

Filtration is the main process in the system of swimming pool water treatment and its aim is to remove solids of varying dispersion from the water. In this way, the filtration protects the remaining parts of the installation against mechanical damage and clogging. It also influences the effects of the subsequent processes, disinfection and water $\mathrm{pH}$ correction.

Swimming pool water filtration systems usually utilize fast filters (pressure, multilayered, sand and gravel or with an additional layer of anthracite, active carbon, zeolite or ones filled with a glass bed) which filter water at $30 \mathrm{~m} / \mathrm{h}[15]$.

Increasingly popular in the treatment of swimming pool water are vacuum filters (open or closed, with frame inserts and a filtration layer) that were previously used for industrial applications.

To make swimming pool water turbidity-free and compliant with current regulations [15], the use of pressure filters have to be combined with a coagulation process that supports water filtration (surface coagulation). In the case of open vacuum filters (mainly due to lower filtration speed, $4-11 \mathrm{~m} / \mathrm{h}$ ) there is no need for an additional support.

The open vacuum filters utilize diatomaceous earth, perlite or cellulose fibers that are washed over the filtration fabric and used as a filtration material. The filtering material in closed vacuum filters is quartz sand of varying granulation or, in justified circumstances, quartz sand and anthracite.

The in-house research [16] allowed to conclude that a swimming pool water treatment system could be accompanied by pressure membrane processes. The tests that have been conducted so far included an attempt to treat the washings by ultrafiltration process. The washings, being a wastewater flux, are characterized by high turbidity and high concentration of solutes, including disinfection byproducts and contaminants present in the chemicals used in the surface coagulation process. The research also described transport and separation properties of the membranes at various process parameters, i.e. type of the membrane material, membrane molar mass cut-off and transmembrane filtration pressure $(\Delta \mathrm{P})$. Fig. 2 shows the separating capabilities of membranes in terms of contaminants removal in a single ultrafiltration process described by absorbance retention coefficient in ultraviolet radiation $\mathrm{UV}_{254}$ and turbidity coefficient. During the ultrafiltration process, high values of turbidity retention coefficient were achieved (above 95\%). Additionally, as the filtration time progressed, the effect of removing the compounds characterized by absorbance in ultraviolet radiation $\mathrm{UV}_{254}$ was increasing. By recovering the treated permeate flux, amounting to $50 \%$, it was reduced by approx. $90 \%$.

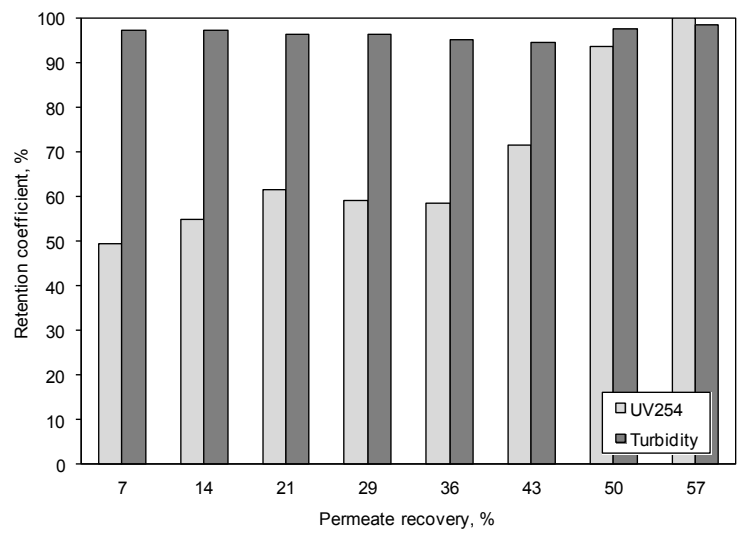

Fig. 2. Changes in the value of the retention factors of pollution in the unit process of ultrafiltration $(\Delta \mathrm{P}=0.2 \mathrm{MPa}$, membrane polimer - polyacrylonitryle) [16].

Membrane pressure processes allow to treat washings to a degree that they can be reused. However, the membrane transport conditions need to be improved by preliminary treatment processes.

\subsection{Disinfection}

Modern technologies for the treatment of swimming pool water, selection of appropriate chemical preparations, high filtering and disinfection efficiency guarantee that the pool water meets the strict requirements in this regard, providing water that is safe for health and comfortable to bathe in.

Although private and therapeutic swimming pools do not necessarily require the use of chemicals, it is not possible (for the time being) to avoid them in the case of public pools. The necessity to use chlorine is dictated by the need to prevent the contamination of water in the swimming pool built for "the masses".

Increasingly popular are systems aiding the final water disinfection with chlorine compounds and UV irradiation (medium and low pressure lamps) or ozonization. Introducing these solutions to swimming pool water treatment systems allows to reduce the amount of chlorine that is added at the final stage of the disinfection process [17]. This, in turn, allows to lower the saturation of chloro-nitrogen compounds that cause allergies, irritation of upper respiratory and digestive system, and which are also mutagenic and responsible for the characteristic unpleasant smell of swimming pool water [18-20].

The disinfectants used in the swimming pool technology include: sodium hypochlorite, chlorine gas, electrolytic chlorine, chlorine dioxide, as well as ozone and UV irradiation in combination with chlorine. Less commonly used are: bromine, iodine and silver ions in combination with chlorine. In swimming pools with 
mineral waters, such as rehabilitation and spa pools, increasingly popular are "low-salinity" technologies during whose operation $\mathrm{NaCl}$ that is added directly to swimming pool basin is subjected to electrolysis. A few swimming pools in Poland (so far, experimentally) support the process of swimming pool water treatment with devices emitting EMF and extended frequencies.

The disinfectant must not be chosen at random. The choice of disinfectant will depend on whether the treatment system is designed for public, leisure, aquapark, sports or a therapeutic swimming pool with, for instance, mineral-rich water. In the last case, it is important to thoroughly analyse the water and perform technological tests to ensure that the reaction of the chosen disinfectant with the compounds naturally present in the water is as mild as possible.

\section{Conclusions}

The identification of organic microcontaminants, including compounds from UV filters and pharmaceutical substances, in swimming pool water makes one consider the effectiveness of the modern technologies of water treatment. It is necessary to establish proper analytic procedures in this regard. The assessment of the quality of swimming pool water and waste fluxes from the treatment installation should by aided by an ecotoxicological analysis. The sets of toxicological tests should also be researched before the selection as these will allow to assess the real effects of the contaminants together with their antagonistic and synergic influence on properly selected test organisms what will, in turn, allow to interpolate the results to a human organism. While searching for a new technology for the treatment of swimming pool water, it is suggested to consider membrane pressure filtration, including the ultrafiltration process.

\section{References}

1. M.G.A. Keuten, F.M. Schets, J.F. Schijven, J.Q. Verberk, J.C. van Dijk, Water Res. 46, 3682 (2012)

2. S.J. Judd, S.H. Black, Water Res. 34, 1611 (2000)

3. D.A. Lambropoulou, D.L. Giokas, V.A. Sakkas, T.A. Albanis, M.I. Karayannis, J. Chrom. A 967, 243 (2002)

4. P. Giokas, M.S. Díaz-Cruz, D. Barceló, Sci. Total Environ. 519, 518 (2015)

5. P. Cuderman, E. Heath, Anal Bioanal Chem. 387, 1343 (2007)

6. C. Zwiener, S.D. Richardson, D.M. de Marini, T. Grummt, T. Glauner, F.H. Frimmel, Environ Sci Technol. 41, 363 (2007)

7. L. Vidal, A. Chisvert, A., Canals, A. Salvador, Talanta 81, 549 (2010)

8. Y. Ekowati et al. Environ Sci Pollut R 23, 14431 (2016)

9. S. Weng, P. Sun, W. Ben, C.H. Huang, L.T., Lee, E.R. Blatchley, Environ. Sci. Technol. Lett. 1, 495 (2014)

10. S. Werle, M. Dudziak, Przem. Chem. 92, 1350 (2013)
11. E. Łaskawiec, E. Kudlek, M. Dudziak, J. Wyczarska-Kokot, Gas Water San. Tech. 9, 330 (2016)

12. E. Łaskawiec, M. Dudziak, J. Wyczarska-Kokot, Ecol. Eng. 50, 210 (2016)

13. E. Łaskawiec, J. Wyczarska-Kokot, M. Dudziak, JCEEA 33, 143 (2016)

14. B.S. Mohan, B.B. Hosett, Environ. Pollut. 98, 233 (1997)

15. DIN 19605: 2016-05: Festbettfilter zur Wasseraufbereitung - Aufbau und Bestandteile

16. E. Łaskawiec, M. Dudziak, J. Wyczarska-Kokot, COBRABiD 4, 238 (2016)

17. J. Wyczarska-Kokot, RI 12, 96 (2009)

18. J. Wyczarska-Kokot, Ochr. Sr. 36, 37 (2014)

19. J. Wyczarska-Kokot, Ecol. Chem. Eng. S 22, 27 (2015)

20. J. Wyczarska-Kokot, Ecol. Chem. Eng. S 23, 447 (2016) 